\title{
Financial Video Games: A Financial Literacy Tool for Social Workers
}

\author{
Kristin Richards \\ Department of Social Work, Mississippi Valley State University \\ 14000 Highway 82 West, Itta Bena, MS 38941, USA \\ Tel: 1-662-254-3365 E-mail: Kvancerichards@gmail.com \\ Jaclyn M. Williams \\ College of Social Work, Florida State University \\ 296 Champions Way, Tallahassee, FL 32306, USA \\ Tel: 1-305-588-6159Ｅ-mail: jmw03u@my.fsu.edu
}

Thomas E. Smith

College of Social Work, Florida State University

296 Champions Way, Tallahassee, FL 32306, USA

Tel: 1-850-645-9599 E-mail: tsmith@fsu.edu

Bruce A. Thyer

College of Social Work, Florida State University

296 Champions Way, Tallahassee, FL 32306, USA

Tel: 1-850-645-4792Ｅ-mail: Bthyer@fsu.edu

Received: February 19, 2015 Accepted: April 29, 2015 Published: May 18, 2015

doi:10.5296/ijsw.v2i1.7130 URL: http://dx.doi.org/10.5296/ijsw.v2i1.7130 


\title{
II Macrothink \\ International Journal of Social Work \\ ISSN 2332-7278 \\ 2015, Vol. 2, No. 1
}

\begin{abstract}
The purpose of this article is to describe a new approach to practice for social workers, providing financial education services to their clients through the use of personal-finance video games. Addressing the financial concerns of individuals and families has long been part of social work practice. However, video games designed for educational purposes (i.e. digital game-based learning) provide a new interactive teaching method which emphasizes experiential learning. Some technological advantages to using video games for educational purposes are: interactivity, accessibility, individualization, low cost per user, the ease of updating the content, and the attractiveness of the graphics. Educational video games support and strengthen: school achievement, cognitive abilities, motivation towards learning, attention and concentration. Overall, the literature indicates that digital game-based learning is a viable and promising method for social workers to provide financial educational services to their clients.
\end{abstract}

Keywords: Financial literacy, Videogames, Social work, Financial education, Digital game-based learning, Finance, Literacy 


\section{Introduction}

The purpose of this article is to present to describe a new method of service delivery for social workers who provide financial literacy services, personal-finance video games. This article will provide background information regarding the role of video games and education, explore current digital game-based research literature, and describe video games currently available for social workers to increase their clients' financial literacy. Addressing the financial concerns of individuals and families has long been part of the practice ethos of the social work profession (Engelbrecht, 2008). Concerned about family finances, Mary Richmond (1917) included financial concerns in her social diagnostic process, "[paving] the way for the contribution of social work to financial literacy of financially vulnerable people" (as cited in Engelbrecht, 2008, p. 256). Jane Addams dedicated her career to working with low-income individuals in settlement houses which provided financial counseling and budgeting education (Rupured, Most, \& Sherraden, 2000).

Today, social workers continue to work with individuals facing precarious financial situations (Kindle, 2010). Individuals lacking a comprehensive understanding of financial concepts are vulnerable to economic problems (Lyons, Chang, \& Scherpf, 2006). Low- to moderate-income individuals, in particular lack access to financial education and financial institutions (Sherraden, Laux, \& Kaufman, 2007). An estimated 10 million Americans do not have a bank account (Caskey, 2002) and it claimed that persons who lack the resources and skills to maintain a bank account are likely to be duped by predatory financial practices (Birkenmaier \& Curley, 2009).

Although the necessity of financial literacy may be obvious, its definition is elusive, encompassing knowledge, ability, behavior, and experiences (Hung, Parker, \& Yoong, 2009). The President's Advisory Council on Financial Literacy (2008, p. 4) defines financial literacy as "the ability to use knowledge and skills to manage financial resources effectively for a lifetime of financial well-being." Vitt et al. (2000, p. xii) defines financial literacy in a more comprehensive manner:

Personal financial literacy is the ability to read, analyze, manage and write about the personal financial conditions that affect material well-being. It includes the ability to discern financial choices, discuss money and financial issues without (or despite) discomfort, plan for the future, and respond competently to life events that affect every day financial decisions, including events in the general economy.

Accordingly, social workers should recognize the unique financial situations faced by clients and reinforce the positive steps taken to enhance their financial stability. Working together, social workers can assist in the development of financial goals and link their clients with tools and services that promote greater financial understanding (Johnson \& Sherraden, 2007; Lapp, 2010). However, financial education by itself does not suffice. Financial education must also emphasize the psychological and sociological characteristics of personal finance as well as access to financial institutions (Jump\$tart Coalition, 2011).

The importance of psychological and sociological variables is highlighted by both behavioral and neoclassical economics models. The former theory posits that individuals are seemingly irrational with respect to their personal finances (Thaler \& Mullainathan, 2008). By contrast, 


\section{MInstitute Macrothink $_{\text {Int }}$}

International Journal of Social Work

ISSN 2332-7278

2015, Vol. 2, No. 1

within the neoclassical framework, individuals are conceptualized as "unemotional maximizers" or homo economicus (Thaler \& Mullainathan, 2008). Neoclassical economic theory further assumes that individuals have boundless rationality, selfishness, and self-control. Instead, Thaler (2000), the father of behavioral economics, stresses that individuals are prone to fallible knowledge and behaviors. Behavioral economics was developed on the premise that neoclassical economic theory draws an incomplete picture of human behavior within the financial marketplace.

Scholars within the behavioral economics field have identified several individual characteristics influencing financial decision-making. For instance, Laibson (1997) focuses on the lack of self-control and its effect on consumers making commitment decisions as a means of avoiding temptation to spend even when the pay-off is limited (e.g., low interest rates in Christmas Club savings accounts). Laibson (1997) also suggests individuals engage in hyperbolic (exaggerated) or delayed discounting procedures. For example, this year, an employee might decide to begin contributing to their 401(k) account next year. However, when next year arrives, that employee may postpone contributions for an additional year. Simply put, long deferred strong positive consequences are often outweighed by smaller but more immediate benefits. Beverly et al. (2008) propose that one's future orientation is an important component of successful savings behavior. Future orientation is defined as "a willingness to invest in one's future, even when one must postpone pleasure" (Beverly et al., 2008, p. 17).

Recently, behavioral economists have referred to this ability to delay gratification as self-control, with self-control defined by Baumeister, Vohs, and Tice (2007) as "the capacity for altering one's own responses, especially to bring them into line with standards...to support the pursuit of long-term goals" (p. 351). Numerous studies within behavioral economics demonstrate individuals find it difficult to resist the "urge to splurge" in order to stay within their budget or to save (Beverly et al., 2008). As saving requires the postponement of consumption, lack of financial self-control often leads to under-saving - notably so for retirement (O'Donoghue \& Rabin, 1998). The good news, however, is that focused self-control efforts in one area, such as curbing spending, can be carried over into other facets of individual behavior (Baumeister, Vohs, \& Tice, 2007).

Ariely (2009) suggests that people are predictably irrational. This is synonymous with the economic term 'bounded rationality'. Consumers are easily manipulated when having too many choices leads to feelings of being overwhelmed and fatigued. In an increasingly complex financial environment, consumers are clearly at risk. There are a myriad of financial products, investment vehicles, and services to choose from. It is difficult enough to read, discern, and compare the terms and conditions of two products, but when dozens are available, individuals may feel defeated and not participate at all. Congruently, when a default option is presented, such as $401(\mathrm{k})$ investment option, individuals may consider the default to be the best choice, due to laziness, procrastination, confusion, or hesitancy to make a different choice (Boshara, Gannon, Mandell, Phillips, \& Sass, 2010; Center for Social Development, n.d.). Defaults like this often serve as heuristics, or mental shortcuts, halting the decision-making process without examining alternatives (Simon, Egidi, Viale, \& Marris, 1992). Limited cognitive abilities lead to repeated poor financial decisions. The research of 
Cole and Shastry (2009) demonstrates that cognitive ability is correlated with participation within financial markets. As individuals age, cognitive abilities decline; as a result, financial behavior is impacted (Xiao et al., 2010). Agarwal, Driscoll, Gabaix, and Laibson (2009) found that the ability to make sound financial choices follows a U-shaped curve with respect to age with younger and older individuals making poorer financial choices. Financial sophistication increases in the middle ages with an estimated peak at age of 53. Mathematical reasoning and computational abilities are associated with financial knowledge and behavior. Benjamin, Brown, and Shapiro (2006) found mathematical reasoning capability to be highly correlated with the ability to act patiently_an important skill when making financial decisions with long-term consequences. Christelis, Jappelli, and Padula (2008) found mathematical skills to be predictive of stock ownership, and McArdle, Smith and Willis (2009) found it to be an important indicator of total asset holdings (as cited in Xiao et al., 2010). Recognizing that all individuals are not especially skilled in mathematical reasoning, findings such as these have important implications.

There are various non-Western approaches to conceptualizing clients' strengths and virtues, and some of these also have applicability towards enhancing a social worker's efforts at improving financial literacy. While traditional Confucian principles do not focus on the acquisition of money or of material possessions, the ability of properly care for one's family, including filial obligations to parents, is highly valued. Helping clients stabilize their own finances and to get out of debt, and avoid future debt is completely congruent with Asian ethical guidelines (see Snow \& Trivigno, 2014). Cautiousness has been shown to be a highly prized personal characteristic among Chinese individuals (see Duan, Ho, Yu, Tang, Zhang, Li, \& Yuen, 2012; Duan, Ho, Bai, \& Tang, 2013), and this value is also consistent with financial literacy efforts aimed at assisting both poor and well-to-do individuals.

Tversky and Kahneman (1974) found that people rely on heuristics or rules of thumb to reduce complex tasks in making judgments. While these mental shortcuts can be useful, they can also lead to systematic errors. Two types of heuristics identified by Tversky and Kahneman (1974) include the 'availability' and 'anchoring and adjustment' heuristics. Availability involves assessing risk by considering examples which easily come to mind. This technique biases decisions towards large-scale or more recent events as they are easier to recall. Decisions to take precaution, such as purchasing flood insurance immediately following a hurricane, are often explained by this practice (Thaler \& Sunstein, 2008). Anchoring and adjustment involves starting with something known and making adjustments as needed. The adjustments are typically insufficient, resulting in bias (Thaler \& Sunstein, 2008). Anchors can serve as a component of choice architecture. For instance, when an employee chooses to contribute to their $401(\mathrm{k})$ program, a range of contribution amount options, such as $\$ 100, \$ 250, \$ 500$, or $\$ 1000$, could influence the amount of money the employee decides to contribute to their retirement savings each pay period. Research demonstrates "the more you ask for, the more you tend to get" (Thaler \& Sunstein, 2008, p. 24). The lack of education and training in personal finance and economic theory complicates assisting financially struggling clients. As a result, clinicians may be ill-equipped to address clients' financial needs (Sherraden, Laux, \& Kaufman, 2007). Instead, clinicians are consigned to educate themselves about financial literacy and its educational tools. While 
social work education appears to be slow in adapting such training into the core curriculum, scholars from other disciplines have taken the initiative to better assist individuals and families within the public and private sectors (Collins, 2011; Maton, Maton, \& Martin, 2010). The goal, of course, is not for social workers to become financial experts, but rather for social workers to become attuned to the underlying financial problems of clients. With increased knowledge, social workers can equip their clients with financial education resources, address underlying thoughts and feelings regarding money, and make appropriate referrals for financial services.

There are encouraging signs that the social work profession is beginning efforts to boost the financial education of their clientele (Despard \& Chowa, 2010). Two notable examples are the Individual Development Accounts (IDAs) and Childhood Development Accounts (CDAs) promulgated by social work faculty at Washington University. IDAs are asset development programs which provide participants with financial education services (Richards \& Thyer, 2011). Outside of IDAs, social workers are using other innovative personal finance interventions to better assist their bereft clients (Despard \& Chowa, 2010). However, not all clients are ready to undertake the arduous task of becoming financially literate. Although there are many advantages in becoming financially literate, clients are apparently not ready for change for such changes in their lifestyles. For such clients, a gradual introduction to financial literacy is necessary. The remainder of this paper is devoted to the discussion of one such strategy: the use of video games.

\section{Video Games and Education}

Video games have long been a popular entertainment medium for children and young adults (Dorman, 1997; Papastergiou, 2009b; Prensky, 2003). A 'video game' refers to "an electronic or computerized game played by manipulating images on a video display or television screen" (Beale, Kato, Marin-Bowling, Guthrie, \& Cole, 2007, p. 264). Recently, researchers from different fields including psychology, pediatrics, medicine, and physical education have investigated the use of video games for educational purposes (Beale et al., 2007; Papastergiou, 2009b; Rosas et al., 2003). Prensky (2003) termed the use of video games designed for educational purposes as 'digital game-based learning.' Video games provide individuals with an interactive and experiential learning experience that shifts the educational focus from a teacher-centered learning environment to a student-centered learning environment (Squire, 2008; Watson, Mong, \& Harris, 2009). Digital game-based learning has been described as "more enjoyable, more interesting, and, thus, more effective than traditional learning modes" (Papastergiou, 2009b, p. 603).

Advantages in using video games include the interactive nature of the games, accessibility, ability to individualize the games, low cost per user, ease of updating the content, and attractive features such as virtual reality and animation (Beale et al., 2007). Academic benefits include video games which can support and strengthen school achievement, cognitive abilities, motivation towards learning, attention and concentration (Rosas et al., 2003). School achievement includes improvement in algebra and reading comprehension, and spelling. Improvements in cognitive abilities include developing different learning styles, complex thinking skills, self-regulated learning, and strategic planning. Students have displayed more motivation to learn when using such games compared to traditional teaching 


\section{$\triangle$ Macrothink}

methods. Finally, because students are more motivated, they also display an increase in attention and concentration. Many social work clients, particularly younger ones, are already familiar with videogames, which renders this means of delivering financial education content an effective medium.

Beale et al. (2007) investigated the usefulness of a psychoeducational video game on increasing cancer-related knowledge in young cancer patients. Three hundred and seventy-five young adult and adolescent cancer patients were randomly assigned to either receive a commercial video game (i.e., control group) or both the commercial video game and an educational video game on cancer called Re-Mission (i.e., intervention group). Participants played the games at least an hour a week for 3 months. Participants' cancer knowledge was tested at baseline, one month, and three months. Both groups improved significantly in cancer knowledge scores over 3 months with the intervention group improving significantly more compared to the control group indicating that the educational video game was successful in increasing patient knowledge about cancer.

Students from six schools participated in a study by Rosas et al. (2003) to evaluate the use of educational video games for first and second grade students. Four schools served as no-treatment control schools ( $\mathrm{n}=169$ students who did not play any video games), and two schools had both experimental $(n=758$ students played educational video games daily during school for 12 weeks) and no-treatment control ( $\mathrm{n}=347$ students did not play video games) conditions. The percentage of children paying attention while playing the video game was significantly higher and displayed significantly better behavior than during class sessions without the video games.

Watson et al. (2011) reported on a case study involving the use of a video game called 'Making History' in a $10^{\text {th }}$ grade high school history class. The game was used to educate students about World War II. Four classes involving a total of 94 students participated in the study. Student engagement was identified by the teacher as his primary motive for introducing the educational video game into the class curriculum. Researchers found that student engagement was enhanced by the hands-on aspect of the game, by the entertaining nature of the game, and by the games challenging aspects. The teacher was also engaged in the video game portions of the class as he was asked to interpret both the environmental context of the game and the situations with which the students were involved throughout the course of the game. The classroom dynamics were changed from a teacher-centric classroom with passive students to a student-centered classroom with active students.

In 2009, Papastergiou reported a comparative study of video games used in high school computer science education. Eighty-eight students were randomly assigned to two groups: the treatment group $(n=47)$ used an educational video game to learn about computer memory, while the control group $(\mathrm{n}=41)$ used an alternative, non-gaming computer application (i.e. a website) to learn. A Computer Memory Knowledge Test was given at both pretest and posttest. The students who used the educational video game scored significantly higher on the posttest than students in the non-gaming group. Students in the gaming group also found the experience more "engaging, effective, active and 'relaxed"" (Papastergiou, 2009a, p. 10) than students who were in the control group.

Overall, the literature indicates that digital game-based learning is a viable and promising 


\section{Ml Macrothink}

International Journal of Social Work

ISSN 2332-7278

2015, Vol. 2, No. 1

alternative for delivering educational content. Financial education could particularly benefit from digital game-based learning (Way \& Wong, 2010), given its success in other educational subjects. This medium provides an opportunity for the expansion of knowledge and consciousness-raising as topics such as cash versus credit, wants versus needs, saving versus spending can be explored through either quiz-based games or by controlling the choices and behaviors cybernetic characters. Through positive stimuli, structure, and repetition, which serves as entertainment rather than monotony, financial skills and abilities may improve - at least with respect to the game.

Future research is needed to demonstrate whether this improvement within games will transfer to real world financial experiences. With the frequency of on-line shopping and banking, these simulated experiences are not so far removed from actual experiences - at least for some players. Certainly, self-evaluation and decision making are necessary components needed to translate gaming experiences to practical application. Congruent with behavioral economics, it is understood that psychological characteristics may impede the transition from game to reality. Optimism lies, however in the learner-centered approach which undergirds technology-based financial education. Way and Wong (2010) emphasize the ecological model to better meet the financial literacy needs of vulnerable populations where individual characteristics as well as interpersonal, community-based, and system-level characteristics are taken into account.

\section{Financial Education Videogame Resources}

While technology-based financial education continues to evolve, the following internet-based video games are presented as currently available free resources for social workers to better meet the financial literacy needs of their clients. It should be noted, however, that this list is in no way exhaustive.

Bite Club, Farm Blitz, Celebrity Calamity, and Groove Nation are financial literacy games developed by the Doorways 2 Dreams Fund (D2D), part of RAND's Financial Literacy Center. These games are targeted towards low-income, minority adults with a limited understanding of the English language. As reported by the Financial Literacy Center (2011), these games "have great potential because they facilitate repetitive engagement with lessons [and] create a 'performative' learning environment" (Tufano, Flacke, \& Maynard, 2011, p. 1). Bite Club (http://financialentertainment.org/play/biteclub.html) is set within the context of a club for vampires and is accompanied by a dance beat. Players are required to face the dialectics of personal finance: meeting current consumption needs, eliminating debt, and saving for retirement. By playing the game, a greater understanding of annual percentage rate (APR) and its impact on debt repayment is developed.

Farm Blitz (http://financialentertainment.org/play/farmblitz.html) is set 'down on the farm' and is complete with music. It is reminiscent of the popular game Farmville available on Facebook. On this farm, however, debt exponentially multiplies like bunnies. Players manage debt and savings but will also need to prepare for financial emergencies, due to, for example, catastrophic weather conditions. By playing the game, a greater understanding of high-interest, short term debt, compound interest, and net worth is developed.

Celebrity Calamity (http://financialentertainment.org/play/celebritycalamity.html) is 
marketed towards women ages 18-35. Players take on the role of financial manager for a celebrity who has difficulty keeping her finances in order. The celebrity asks the financial manager to make specific purchases for upcoming trips, to share with her friends, or for entertainment purposes. The player chooses whether to pay with a credit card or debit card and as a result gains greater insight into finance charges, credit limits, fees, and annual percentage rates (APR). Beyond managing finances, players must work to ensure the celebrity's happiness. The addition of this psychological element is interesting as research demonstrates that income can have an impact on happiness (Kahneman \& Deaton, 2010).

Also marketed towards women ages 18-35, Groove Nation is about "danc[ing] your way to a healthy budget" (http://financialentertainment.org/play/groovenation.html). Similar to Celebrity Calamity, players serve as financial managers. Income, fixed and variable costs, debt, short- and long-term savings, as well as upgrades for dance performances are managed. The financial manager learns to set aside earnings from the dancer's job and performances in order to make it from town to town. As the location changes, so do fixed costs, such as rent. Groove Nation teaches players how to manage current consumption and save for future goals.

Football enthusiasts will enjoy Financial Football developed by Visa. This (http://www.practicalmoneyskills.com/games/trainingcamp/ff/play/), game is playable for either one or two clients and is appropriate for three distinct age groups: Rookie, 11-14, Pro, 14-18, and Hall of Fame, 18+. Players choose their sports teams and head out to the field for the coin flip. Plays are chosen based on level of difficulty, which corresponds with a financial question. If the question is answered correctly, the team moves down the field. Age-appropriate lessons on credit, debt, savings, spending, and financial planning are also provided. For those individuals who prefer a different type of football, Financial Soccer is also available (http://www.financialsoccer.com/).

Debt Ski (http://www.indebted.com/the-game/debtski/) is a fairly simple financial literacy game developed by mtvU, MTV's college network, and the Peter G. Peterson Foundation. A piggy bank drives a jet ski through rough waters, collecting coins, wanted items, and basic necessities. If sufficient funds are not saved, a financial tsunami could set the player back. This game drives home a prudent message: in order to financially succeed, you must live within your means. This includes maximizing saving and minimizing debt. A happiness score is also included in this game. It is impacted by debt, savings, and the provision of life necessities.

\section{Conclusion}

The role of personal finance education continues to play a larger and larger role in how people plan their future (Fox, Bartholomae, \& Lee, 2005). The decline of planned benefit retirements programmes, erratic $401 \mathrm{k}$ funds, and high unemployment rates have increased the need for financial literacy services for social work clients. Videogames provides a creative venue to educate people in personal finance. However, focusing on financial literacy only begins this process; other efforts will be necessary to move forward to ensure increased financial education. As stated earlier, behavioral economics theory suggests the complexity of what will be necessary to increase a person's financial literacy. Because of these variables, a person's financial behavior can be seemingly irrational. A postulate of neoclassical economic theory is that people routinely maximize their financial goals and have perfect knowledge 
with which to make completely rational decisions. Whether under behavioral or neoclassical economics, by itself a simple video game is hardly likely to provide the knowledge or initiative needed to accomplish a person's financial goals.

Any strategy that is aimed at increasing effective financial behaviors will be required to address these factors. Notwithstanding this formidable challenge, use of online video games provides a much needed step in the right direction. By instilling familiarity with concepts related to personal finance, social work clients will be more likely to undertake the efforts that are needed to become financial literate. In addition, success in video games will undoubtedly boost a person's self-efficacy although there is irony to encourage clients to indulge in video games. However, if video games provide incremental increases in a person's financial efficacy, then game-play ceases to be an empty activity, serving educational needs and enhancing positive psychosocial functioning. However, four factors may reduce their effectiveness. First, men may be more accustomed to the use of video games, relative to women. Second, the use of financial games alone are unlikely ensure significant increases in financial capacity. Enhanced earning via employment will also be crucial for most social work clients and financial literacy videogames are not focused on this domain. Third, people who are faced with economic difficulties may be reluctant to play video games as a method of increasing their knowledge of personal finance, perhaps viewing the game as a trivial activity. This requires that social workers lay the groundwork and establish a clear rationale for the use of these games. Fourth, there is a digital divide in which affluent clientele are more likely to possess existing skills in playing videogames. Fifth, education cannot substitute for action. A significant change in financial behaviors may well necessitate a lifestyle change. Helping the unemployed find rewarding work, the underemployed find a more remunerative job, the under-educated to acquired appropriate credentials (e.g., GED, high school diploma, vocational training, college credits or perhaps a degree), curtailing impulsive buying, and reducing expensive habits (e.g., smoking, drinking, drug abuse) are all crucial elements towards achieving economic well-being that financial literacy videogames do not address. We have developed treatment manuals and workbooks aimed at facilitating the delivery of financial therapy to clients in one-to-one and group work contexts (Smith, Nelson, Richards \& Hamel, 2012a, 2012b). Resources which may used in conjunction with, or in lieu of, financial literacy videogames.

As a result of the global recession, a host of public, private, and nonprofit organizations have recognized the importance of financial literacy and some have embraced the digital world as an effective medium for such education. As we move further into the 21 st century, there is greater demand for on-line education. Learning that is both interactive and fun for students and teachers alike, may in fact, be more effective (Prensky, 2001). Digital game-based learning may be the exciting venue ready for the primary learning of financial literacy concepts.

Although financial video games may be a significant resource for social workers to use with clients, it is naïve to overlook the digital divide that exists in America. The digital divide is between people who have access to technology and those who do not (Drori, 2010). This divide is often thought to be due to income (i.e., those who can afford to purchase technology use it and those who cannot afford it do not use it). This is not completely true (Jackson, 
Barbatsis, von Eye, Biocca, \& Zhao, 2003), but it is enough of a concern that it needs to be addressed when discussing a technology-based intervention for low income individuals. In a large part, enabling online access for impoverished clients should be a responsibility of the social worker who wishes to use this medium. Linking clients with services and resources is part of what social workers do. Nevertheless, some suggestions to bridging the digital access gap are: 1) to use that social worker's computer during sessions with the client, or 2) to introduce the client to a computer in a local community center or library. Digital game-based learning is only one tool in the social worker's toolbox and would not be appropriate in all situations. It is, however, a potentially useful option if it can be utilized. Actual empirical outcome studies demonstrating the effectiveness of the financial literacy videogames are necessary, since few have been systematically evaluated. Pending the publication of such studies however, social workers may opt to promote the use financial literacy videogames with their economically distressed clients, given the low cost and face validity of these programs.

\section{References}

Agarwal, S., Driscoll, J. C., Gabaix, X., \& Laibson, D. (2009). The age of reason: Financial decisions over the lifecycle (Working Paper). Boston, MA: Harvard University and MIT.

Ariely, D. (2009). Predictably irrational. New York: HarperCollins Publishers.

Baumeister, R. F., Vohs, K. D., \& Tice, D. M. (2007). The strength model of self-control. Current Directions in Psychological Science, 16, 351-355. http://dx.doi.org/10.1111/j.1467-8721.2007.00534.x

Beale, I. L., Kato, P. M., Marin-Bowling, V. M., Guthrie, N., \& Cole, S. W. (2007). Improvement in cancer-related knowledge following use of a psychoeducational video game for adolescents and young adults with cancer. Journal of Adolescent Health, 41, 263-270. http://dx.doi.org/10.1016/j.jadohealth.2007.04.006

Beverly, S., Sherraden, M., Zhan, M., iam Shanks, T. R., Nam, Y., \& Cramer, R. (2008). Determinants of asset building. Retrieved from http://www.urban.org/UploadedPDF/411650_asset_building.pdf

Bingaman, J. (2011). Summary of the Automatic IRA Act of 2011. Retrieved from http://bingaman.senate.gov/policy/autoira_09142011.pdf

Birkenmaier, J., \& Curley, J. (2009). Financial credit: Social work's role in empowering low-income families. Journal of Community Practice, 17, 251-268. http://dx.doi.org/10.1080/10705420903117973

Boshara, R., Gannon, J., Mandell, L., Phillips, J. W. R., \& Sass, S. (2010). Consumer trends in the public, private, and nonprofit sector. Retrieved from http://www.nefe.org/LinkClick.aspx?fileticket=B4PXjKtMqJQ\%3d\&tabid=934

Caskey, J. P. (2002). Bringing unbanked households in the banking system. Retrieved from http://www.brookings.edu/articles/2002/01metropolitanpolicy_caskey.aspx

Center for Financial Security. (2011). About us. Retrieved from http://cfs.wisc.edu/about-us.aspx

Center for Financial Social Work. (2011). About. Retrieved from 
http://www.financialsocialwork.com/about

Center for Social Development. (n.d.). Overview of savings theory. Retrieved from http://csd.wustl.edu/AssetBuilding/Documents/Savings_Theory.pdf

Christelis, D., Jappelli, T., \& Padula, M. (2008). Cognitive abilities and portfolio choice. http://dx.doi.org/10.2139/ssrn.1275284

Cole, S. A. \& Shastry, G. K. (2009, February). Smart money: The effect of education, cognitive ability, and financial literacy on financial market participation (Working Paper 09-071). Boston, MA: Harvard Business School Finance.

Collins, J. M. (2011). Integrating financial capacity building into public programs. Retrieved from

http://cfs.wisc.edu/PublicationsBriefs/Integrating_Financial_Capacity_Building_Into_Public_ Programs.pdf

Despard, M. R., \& Chowa, G. A. N. (2010). Social workers' interest in building individuals financial capabilities. Journal of Financial Therapy, 1(1), 23-41. http://dx.doi.org/10.4148/jft.v1i1.257

Dorman, S. M. (1997). Video and computer games: Effect on children and implications for health education. Journal of School Health, 67, 133-138. http://dx.doi.org/10.1111/j.1746-1561.1997.tb03432.x

Duan, W., Ho, S., M. Y., Bai, Y., \& Tang, X. (2013). Psychometric evaluation of the Chinese virtues questionnaire. Research on Social Work Practice, 23, 336-345. http://dx.doi.org/10.1177/1049731513477214

Duan, W., Ho, S. M. Y., Bai, Y., Tang, X., Zhang, Y. Li, T., \& Yuen, T. (2012). Factor structure of the Chinese Virtues Questionnaire. Research on Social Work Practice, 22, 680-688. http://dx.doi.org/10.1177/1049731512450074

Engelbrecht, L. (2008). The scope of financial literacy education: A poverty alleviation tool in social work? Social Work/Maatskaplike Werk, 44, 252-262.

Fox, J., Bartholomae, S., \& Lee, J. (2005). Building the case for financial education. Journal of Consumer Affairs, 39, 195-214. http://dx.doi.org/10.1111/j.1745-6606.2005.00009.x

Hung, A. A., Parker, A. M. and Yoong, J. K. (2009). Defining and measuring financial literacy. http://dx.doi.org/10.2139/ssrn.1498674

Johnson, E., \& Sherraden, M. S. (2007). From financial literacy to financial capability among youth. Journal of Sociology \& Social Welfare, 34, 119-146.

Jump\$tart Coalition. (2011). http://www.jumpstart.org/faq.html

Kahneman, D. \& Deaton, A. (2010). High income improves evaluation of life but not emotional well-being. Proceedings of the National Academy of Sciences of the United States of America, 107, 16489-16493. http://dx.doi.org/10.1073/pnas.1011492107

Laibson, D. (1997). Golden eggs and hyperbolic discounting. Quarterly Journal of Economics, 112, 443-477. http://dx.doi.org/10.1162/003355397555253

Lapp, W. M. (2010). Behavioral models for driving prosperity for low income people: EARN's model of financial self-efficacy. Retrieved from http://www.earn.org/static/uploads/files/EARN_Whitepaper_Behavioral_Models_Financial_ 
Self_Efficacy_Nov2010.pdf.pdf

Lyons, A. C. Chang, Y., \& Scherpf, E. M. (2006). Translating financial education into behavior change for low-income populations. Financial Counseling and Planning, 17, 27-45.

Maton, C. C., Maton, M., \& Martin, W. M. (2010). Collaborating with a financial therapist: The why, who, what, and how. Journal of Financial Planning, 23, 62-70.

O'Donoghue, T., \& Rabin, M. (1998). Procrastination in preparing for retirement. Retrieved from http://elsa.berkeley.edu/ rabin/retire.pdf

Papastergiou, M. (2009a). Digital game-based learning in high school computer science education: Impact on educational effectiveness and student motivation. Computers \& Education, 52, 1-12. http://dx.doi.org/10.1016/j.compedu.2008.06.004

Papastergiou, M. (2009b). Exploring the potential of computer and video games for health and physical education: A literature review. Computers \& Education, 53, 603-622. http://dx.doi.org/10.1016/j.compedu.2009.04.001

Prensky, M. (2001). The digital game-based learning revolution. In M. Prensky (Eds.), Digital game-based learning (pp. 1-19). New York: McGraw-Hill.

Prensky, M. (2003). Digital game-based learning. ACM Computers in Entertainment, 1(1), 1-4. http://dx.doi.org/10.1145/950566.950596

Richards, K. V., \& Thyer, B. A. Does individual development account participation help the poor? A review. Research on Social Work Practice, 21, 348-362. http://dx.doi.org/10.1177/1049731510395609

Richmond, M. E. (1917). Social diagnosis. New York: Russell Sage Foundation.

Rosas, R., Nussbaum, M., Cumsille, P., Marianov, V., Correa, M., Flores, P., ... Salinas, M. (2003). Beyond Nintendo: Design and assessment of educational video games for first and second grade students. Computers \& Education, 40, 71-94. http://dx.doi.org/10.1016/S0360-1315(02)00099-4

Rupured, M., Most, B. W., \& Sherraden, M. (2000). Improving family financial security: A family economics-social work dialogue. Retrieved from https://www1067.ssldomain.com/afcpe/doc/Vol1129.pdf

Sherraden, M., Laux, S., \& Kaufman, C. (2007). Financial education for social workers. Journal of Community Practice, 15(3), 9-36. http://dx.doi.org/10.1300/J125v15n03_02

Simon, H A. (1994). Behavioral economics. Retrieved from http://octopus.library.cmu.edu/cgi-bin/tiff2pdf/simon/box00079/fld06422/bd10003/doc0003/si mon.pdf

Simon, H. A., Egidi, M., Viale, R., \& Marris, R. (1992). Economics, bounded rationality, and the cognitive revolution. Cheltenham, UK: Edward Elgar Publishing Ltd.

Smith, T. E., Nelson, R., Richards, K. V. \& Hamel, V. (2012). Financial therapy:Five steps to financial freedom. Tallahassee, FL: Southeastern Professional Books.

Smith, T. E., Nelson, R., Richards, K. V. \& Hamel, V. (2012). Guide to financial therapy: Handouts and forms. Tallahassee, FL: Southeastern Professional Books.

Snow, N. E. \& Trivigno, F. V. (Eds.) (2014). The philosophy and psychology of character and happiness. New York: Taylor \& Francis. 


\section{Macrothink}

International Journal of Social Work ISSN 2332-7278 2015, Vol. 2, No. 1

Squire, K. D. (2008). Video game-based learning: An emerging paradigm for instruction. Performance Improvement Quarterly, 21(2), 7-35. http://dx.doi.org/10.1002/piq.20020

Suiter, M. \& Meszaros, B. T. (2005). Teaching about saving and investing in the elementary and middle school grades. Social Education, 69, 92-95.

Thaler, R. H. (2000). From homo economicus to homo sapiens. Journal of Economic Perspectives, 14, 133-141. http://dx.doi.org/10.1257/jep.14.1.133

Thaler, R. H., \& Mullainathan, S. (2008). How behavioral economics differs from traditional economics. In D. R. Henderson, (Ed.). The concise encyclopedia of economics (pp. 34-37). Indianapolis, IN: Liberty Fund.

Tufano, P., Flacke, T., \& Maynard, N. (2011). Project: Better financial decision making among low-income and minority groups. Retrieved from http://www.rand.org/labor/centers/

financial-literacy/projects/decisionmaking-low-income-minority.html

Tuzun, H., Yilmaz-Soylu, M., Karakus, T., Inal, Y., \& Kizilkaya, G. (2008). The effects of computer games on primary school students' achievement and motivation in geography $\begin{array}{lllll}\text { learning. } & \text { Computers } & \& & \text { Education, } & 52,\end{array}$ http://dx.doi.org/10.1016/j.compedu.2008.06.008

Watson, W. R., Mong, C. J., \& Harris, C. A. (2011). A case study of the in-class use of a video game for teaching high school history. Computers \& Education, 56, 466-474. http://dx.doi.org/10.1016/j.compedu.2010.09.007

Way, W. L., \& Wong, N. (2010). Harnessing the power of technology to enhance financial literacy education and personal financial well-being: A review of the literature, proposed model, and action agenda. (CFS Research Brief FLRC 10-6) Retrieved from Center for Financial Security website: http://www.cfs.wisc.edu/Working_Papers/Harnessing_the_Power_of_Technology_to_Enhanc e_Financial_Literacy_Education_and_Personal_Financial_Well-Being_A_Review_of_the_Li terature_Proposed_Model_and_Action_Agenda_WP_10-6.pdf

Van Wormer, K., \& Besthorn, F. H. (2011). Human behavior and the social environment: Groups, communities, and organizations. New York: Oxford University Press, Inc.

Vitt, L. A., Anderson, C., Kent, J., Lyter, D. M., Siegenthaler, J. K., \& Ward, J. (2000). Personal finance and the rush to competence: Financial literacy education in the U.S. Retrieved from http://www.isfs.org/documents-pdfs/rep-finliteracy.pdf

\section{Copyright Disclaimer}

Copyright reserved by the author(s).

This article is an open-access article distributed under the terms and conditions of the Creative Commons Attribution license (http://creativecommons.org/licenses/by/3.0/). 